\title{
Association between Smoking and Dental Caries among People of Kolhapur District, Maharashtra, India
}

INTRODUCTION: Smoking as a public health problem, harms one's general and oral well-being leading to increased morbidity and mortality. AIM: To find out the association between dental caries and smokers (current and past) with non-smokers among people of Kolhapur District, Maharashtra, India.

MATERIALS AND METHODS: The present cross-sectional study was conducted among 1366 (449 smokers, 440 past smokers and 447 nonsmokers), and the patients were divided among three age groups $(35-44,45-60$ and $>60$ years). Data was recorded using a pre-tested, prevalidated questionnaire recording the demographic details and modified DMFT index. The data was analyzed using $\mathrm{t}$ - test, calculation of Odd's Ratio (OR) and logistic regression was applied to find out association, if any using a licensed SPSS version 22.0.

RESULTS: It was revealed that the highest mean DMFT was seen among smokers (3.66 \pm 5.78$)$ followed by past smokers(3.01 \pm 2.66$)$ and nonsmokers (3.01 \pm 2.66$)$. Also, the maximum DMFT was seen among 35-44 years (3.82 \pm 2.4$)$, which was found out to be significant as compared to past -smokers and non-smokers. Odd's ratio analysis revealed that as compared to non-smokers, current smokers and past smokers were 1.6 and 1.1 respectively. The multiple regression analysis revealed that significant difference was seen between smoking(.o1) and age (0.02) with respect to DMFT.

CONCLUSION: Efforts are required by clinicians to educate people about the ill-effects of tobacco and provide tobacco cessation counselling to reduce the burden of morbidity and mortality caused by tobacco.

\section{INTRODUCTION}

The entire scientific community through proven research has pointed out the menace of tobacco consumption, also termed as "a public health nightmare" prevalent among people across the globe. ${ }^{1}$ The CDC (Centers for Disease Control and Prevention) and $\mathrm{WHO}$ proclaim that tobacco use causes nearly 6 million deaths per year and if these trends continue at the same pace, this will cause more than 8 million deaths annually by the year 2030 with $70 \%$ of deaths occurring in the low economy countries. ${ }^{2,3,4}$

The use of tobacco leads to various ill effects, namely cancer, low birth weight, pulmonary, cardiovascular, renal diseases and other dental diseases such as extrinsic stains, halitosis, gingivitis, periodontitis etc. ${ }^{5}$ In addition, second hand smoke and Environmental Tobacco Smoke (ETS) also affect the person around a smoker and thus, cause harm to an otherwise non-smoking population. In India, WHO estimates show that approximately $12 \%$ of global smokers belong to India with hukkah smoking more prevalent in rural areas and cigarette smoking more common in urban areas. ${ }^{6}$ Alarmingly, smoking prevalence is on the rise among the young population in India, according to Gavarsana et al. highlighting that $18 \%$ of boys in their respective study sample of college students were found to be smokers. ${ }^{7}$

Dental diseases due to smoking hamper holistic oral health. One of the effects of smoking is dental caries which can progress to complete tooth decay if left unchecked. This condition is undesired and severely compromises the oral health status of the individual. Moreover, dental caries is often a disease that goes undetected until the patient complains of pain in his oral cavity. In India, where the prevalence of dental caries is reported to be $50-60 \%,{ }^{8}$ certain researches report the prevalence to be as high as $82.4 \%$ (urban) ${ }^{9}$ and $80 \%\left(\right.$ rural) ${ }^{10}$ within the age group of $35^{-}$ 44 years. There have been various instances that link the presence of dental caries to smoking. While certain authors ${ }^{11,12}$ state that increased smoking results in lesser prevalence of caries which is mainly attributed to the presence of thiocyanate in saliva. On the contrary, Ludwick W et al. highlighted that amongst those who smoked more than 15 cigarettes per day, the result was an increase in the number of decayed, missing, and filled teeth. ${ }^{13}$

A thorough literature search around the geographic location of Maharashtra found little or no data associating the relationship between smoking and 
dental caries.

Hence, the present study was conducted with the aim to find out the association between dental caries and smokers (current and past) with non-smokers among people of Kolhapur District, Maharashtra, India.

\section{MATERIALS AND METHOD}

The present cross-sectional study was conducted among 1366 (449 smokers, 440 past smokers and 447 non-smokers) people visiting a dental college in Kolhapur District, Maharashtra, India from $1^{\text {st }}$ October 2017 to $31^{\text {st }}$ December, 2017. Prior to conduction of the study, and ethical consent was obtained. The patients were assured of the confidentiality of their data and demographic details and DMFT status were entered in a pre-tested, prevalidated questionnaire by an assistant who stood close to the examiner during the study. The study was conducted by two standardized examiners and two recording clerks.

Inclusion criteria included smokers, past smokers and non-smokers aged more than 35 years. For inclusion in the past smoker's category, it was essential that the patient reported of quitting smoking for more than two years. Patients suffering from any systemic diseases were excluded from the study to avoid the presence of confounding factor(s). Sample size calculation was done by a certified statistician who estimated the sample as 396 400 people in each group. Therefore, to include maximum number of people in each group, the target sample was kept at 480 as to compensate for loss of data due to improper recording and various other factors. The study followed a convenience sampling and the modified DMFT index was used to record the DMFT (Knutson, Klein and Palmer, 1997) status of the patient. The examinations were carried out using a CPITN probe and mouth mirrors in the dental chair using artificial light. Descriptive statistics were applied and the t- test, calculation of Odd's Ratio (OR) and logistic regression was applied to find out association, if any using a licensed SPSS 22.0 software.

\section{RESULTS}

Table 1. depicts the characteristics of the study population. It was seen that while almost an equal number of people were seen in all the groups, the youngest population was seen in the current smoker group $(154,34.3 \%)$ while the oldest were seen in the non-smoker group $(217,48.5 \%)$. The majority of the population in all three groups was males and the highest percentage of people in all the three groups reported brushing once a day. The highest number of people in the non-smoking group also reported brushing once a day $(27,6 \%)$. Continuing the same trend, the maximum number of patients who visited a dentist before belonged to the non-smoker group $(153,30.2 \%)$.

The mean DMFT among current smokers, past smokers and non-smokers is shown in table 2. It was observed that the highest mean DMFT was seen among smokers $(3.66 \pm 5.78)$ followed by past

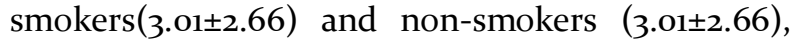
which was found to be significant $(\mathrm{p}=\mathrm{0.02})$. Another observation was the highest number of decayed, missing teeth that were seen in current smokers $(3.81 \pm 7.6,3.08 \pm 4.3)$ with the lowest number of filled teeth (0.97 \pm 1.2$)$. An almost equal amount of missing teeth was seen among past smokers $(2.65 \pm 3.9)$ and non-smokers $(2.55 \pm 6.6)$ while past smokers showed

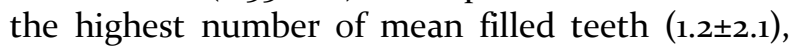
with analysis showing a non-significant value.

Table 3 depicts the mean DMFT among the three age groups. It was observed that the highest mean DMFT was seen among age group of 35-44 years (3.82 \pm 2.4$)$, which was significant as compared to past-smokers and non-smokers. Odd's ratio analysis revealed that as compared to non-smokers, current smokers and past smokers were 1.6 and 1.1 respectively.

Given the multiplicity of factors affecting the DMFT index, multiple regression analysis was performed (Table 4). Significant difference was seen between smoking(.o1) and age (0.02). It was generally observed that dental caries increased with age among smokers.

\section{DISCUSSION}

The present study was done with the aim to find out the association between dental caries and smokers (current and past) and comparison with nonsmokers among people of ? region. The study revealed that the mean DMFT in smokers was $3.66 \pm 5.78,3.01 \pm 2.66$ in past smokers and $2.32 \pm 1.81$ among non-smokers. 
The mean DMFT recorded among smokers of the present study $(3.66 \pm 5.78)$ is lower as compared to Aguilar-Zinser et al. $(8.80 \pm 6.56)^{14}$ and Badel T et al. $(7.32)^{15}$ and in slight agreement with Rooban T et al. ${ }^{16}$ (4.09). Such variations can be attributed to differences in smoking practices (hukkah, bidi, kreteks etc,) and genetic makeup of individuals that differ across the globe. Also, the difference of mean DMFT among smokers and non-smokers was found to be significant $(\mathrm{p}=\mathrm{O} .02)$ as supported by Badel $\mathrm{T}$ et al.15 and Shalini P et al. ${ }^{17}$ The results of Hart et al. ${ }^{18}$ disagreed and stated that no significant difference was seen among DMFT status of smokers and nonsmokers.

The findings of the present study also revealed that Smokers were 1.6 times more likely to get caries as compared to non-smokers. This is in agreement to the study by Campus G et al. (OR:1.8). ${ }^{19}$ Other confounding factors that can lead to dental caries are related to dietary changes and exposure to fluoridated drinking water.

The present study is also prone to certain limitations. Firstly, both social desirability bias and recall bias among previous smokers regarding the time of their smoke-free period might have been under-reported. Secondly, the results of studies with convenience sampling is difficult to extrapolate for the general population. However, the aim of the present study was to provide an insight to the current status of dental caries among smokers in this region to render information for future studies.

\section{CONCLUSION}

To tackle the menace of tobacco smoking, it is important that a multisectoral approach be drafted and the people of Kolhapur District, Maharashtra, India should be educated, motivated and re-inforced regarding the ill effects of tobacco on general as well as one's oral health.

\section{REFERENCES}

1. Lancet Editorial. China's unhealthy relations with big tobacco. Lancet 2011;377:180.

2. World Health Organization. WHO Report on the Global Tobacco Epidemic, 2011. Geneva: World Health Organization, 2011 [accessed 2018 Feb 22].

3. Centers for Disease Control and Prevention. Fast Facts. Available from https://www.cdc.gov/tobacco/data statistics/fact s heets/fast facts/index.htm [Accessed on 12th March, 2018]

4. Vellappally S, Fiala Z, Smejkalova J, Jacob V, Shriharsha P. Influence of tobacco use in dental caries development. Cent Eur J Public Health. 2007; 15(3):116-21.

5. Upadhyaya N, Mishra R. A Journey Since 1899 To 2013 Finding Associations between Tobacco Smoking and Dental Caries. Research and Reviews: Journal of Dental Sciences. 2014;2(2):65-72.

6. Chandrupatla SG, Tavares M, Natto ZS. Tobacco Use and Effects of Professional Advice on Smoking Cessation among Youth in India. Asian Pacific journal of cancer prevention: APJCP.2017; 18(7): 1861-7.

7. Gavarasana S, Gorty PV, Allam A. Illiteracy, ignorance and willingness to quit smoking among villagers in India. Japanese Journal of Cancer Research. 1992;83:340-343

8. Shah N. Oral and Dental diseases: Causes, prevention and treatment strategies: Burden of disease, National Commission on Macroeconomics and Health; 2005:275-98.

9. Patro BK, Kumar RB, Goswami B, Mathur VP, Nongkynrih B. Prevalence of dental caries among adults and elderly in an urban resettlement colony of New Delhi. Indian J Dent Res 2008;19: 95-8.

10. Maru AM, Narendran S. Epidemiology of dental caries among adults in a rural area in India. J Contemp Dent Prac 2102;13(3): 382-8.

11. Gibbs MD. Tobacco and dental caries. J Am Coll Dent. 1952;19:365-7.

12. Hart AC. Prevention of decay of the teeth. Dent Items Interest.1899;21(3):153-63.

13. Ludwick W, Massler M. Relation of dental caries experience and gingivitis to cigarette smoking in males 17 to 21 years old (at the Great Lakes Naval Training Center). J Dent Res. 1952;31(3):319-22

14. Aguilar-Zinser V, Irigoyen M.E, Rivera G, Maupomé G, Sánchez-Pérez L, Velázquez C. Cigarette Smoking and Dental Caries among Professional Truck Drivers in Mexico. Caries Res 2008;42:255-62.

15. Badel T, Pavicin SI, Carek AJ, Segovic S. Dental Caries Experience and Tobacco Use in 19-year-old Croatian Army Recruits. Coll. Antropol. 2014;38(2):671-5.

16. Rooban T, Vidya KM, Joshua E, Rao A, Ranganathan S, Rao UK, et al. Tooth decay in alcohol and tobacco abusers. J Oral Maxillofac Pathol. 2011; 15(1): 14-21. 
17. Shalini P, Niramathi K, Ranjith K, Chaly PE, Priyadarashini VI, Nijesh JE. Dental Caries

Experience Among Tobacco Consuming Truck Drivers In North Chennai, India. International Journal of Dental Research \& Development (IJDRD) 2017; 7(1):1-8.
18. Hart GT, Brown DM, Mincer HH. Tobacco use and dental disease. Journal of the Tennessee Dental Association 1995;75(2):25-7.

19. Campus G, Cagetti MG, Senna A, Blasi G, Mascolo A, Demarchi P, et al. Does smoking increase risk for caries? A cross-sectional study in an Italian military academy. Caries Res 2011;45:40-6.

Source of support: Nil, Conflict of interest: None declared

Cite this article as:

Patil YB, Shinde SV, Qureshi A. Association between Smoking and Dental Caries among

People of Kolhapur District, Maharashtra, India. Int Healthcare Res J 2018;2(5):121-125. doi: 10.26440/IHRJ/02_05/191

\section{AUTHOR AFFILIATIONS:}

1. HOD and Reader, Department of Public Health Dentistry, Tatyasaheb Kore Dental College And Research Center, New Pargaon Warnanagar Kolhapur

2. Associate Professor, Department of Dentistry, Prakash Institute of Medical Sciences. Islampur.

3. Post Graduate, Department of Oral and Maxillofacial Surgery, Rajasthan Dental College \& Hospital, Jaipur

\section{Corresponding Author:}

Dr. Yojana B. Patil

HOD and Reader

Department of Public Health Dentistry

Tatyasaheb Kore Dental College and Research

Center, New Pargaon Warnanagar Kolhapur
For article enquiry/author contact details, e-mail at: manuscriptenquiry.ihrj@gmail.com

\section{LEGENDS}

\begin{tabular}{|c|c|c|c|}
\hline Variable & $\begin{array}{l}\text { Current Smokers } \\
\quad \mathrm{N}=554 \\
\% \text { or mean }(\mathrm{SD})\end{array}$ & Past smokers (>2 years) & Non-smokers \\
\hline $\mathbf{N}$ & 449 & 440 & 447 \\
\hline $\begin{array}{c}\text { Age } \\
\text { 35-44 Years } \\
\text { 45-6o Years } \\
\text { > } 60 \text { years }\end{array}$ & $\begin{array}{l}154(34.3) \\
179(39.9) \\
116(25.8)\end{array}$ & $\begin{array}{c}111(25.2) \\
187(42.5) \\
142(32.3)\end{array}$ & $\begin{array}{l}126(28.2) \\
104(23 \cdot 3) \\
217(48.5)\end{array}$ \\
\hline $\begin{array}{l}\text { Gender } \\
\text { Males } \\
\text { Females }\end{array}$ & $\begin{array}{c}440(98.2) \\
9(1.8)\end{array}$ & $\begin{array}{c}438(99.5) \\
2(0.5)\end{array}$ & $\begin{array}{c}440(98.4) \\
7(1.6)\end{array}$ \\
\hline $\begin{array}{c}\text { Tooth brushing } \\
\text { frequency } \\
\text { Once } \\
\text { Twice } \\
\text { thrice }\end{array}$ & $\begin{array}{c}387(86.2) \\
61(13.6) \\
01(0.2)\end{array}$ & $\begin{array}{c}286(65) \\
140(31.9) \\
14(3.1)\end{array}$ & $\begin{array}{c}299(66.9) \\
121(27.1) \\
27(6)\end{array}$ \\
\hline $\begin{array}{c}\text { Visit to dentist } \\
\text { Yes } \\
\text { Never }\end{array}$ & $\begin{array}{c}99(22.1) \\
350(77.9)\end{array}$ & $\begin{array}{c}112(25.4) \\
328(74.6)\end{array}$ & $\begin{array}{l}312(69.8) \\
135(30.2)\end{array}$ \\
\hline
\end{tabular}

Table 1. Sociodemographic Profile of the Patients. 


\begin{tabular}{|l|c|c|c|c|}
\hline & Current smokers & Past Smokers & Non-smokers & P value, t-test \\
\hline Mean DMFT & $3.66 \pm 5.78$ & $3.01 \pm 2.66$ & $2.32 \pm 1.81$ & N.02 \\
\hline $\begin{array}{l}\text { Mean Decayed } \\
\text { teeth }\end{array}$ & $3.81 \pm 7.6$ & $3.25 \pm 2.22$ & $2.5 \pm 5.4$ & NS; \\
\hline Mean Missing teeth & $3.08 \pm 4.3$ & $2.65 \pm 3.9$ & $2.55 \pm 6.6$ & NS \\
\hline Mean Filled Teeth & $0.97 \pm 1.2$ & $1.2 \pm 2.1$ & $1.08 \pm .67$ & NS \\
\hline
\end{tabular}

Table 2. The Mean DMFT among Current Smokers, Past Smokers And Non-Smokers

\begin{tabular}{|l|c|c|c|c|}
\hline & $35-44$ Years & $45-60$ Years & $<6$ years & \multicolumn{2}{c|}{ t-test, $\mathrm{p}$ value } \\
\hline Smokers & $3.82 \pm 2.4(\mathrm{p}=0.001)$ & $2.99 \pm 4.4$ & $2.23 \pm 8.2$ & 0.001 OR: 1.6 \\
\hline Past smokers & $3.34 \pm 3.77$ & $3.0 \pm 1.1$ & $2.31 \pm 3.1$ & NS OR:1.1 \\
\hline Non-smokers & $1.08 \pm 1.25$ & $2.6 \pm 7.1$ & $1.97 \pm 2.6$ & NS -Constant \\
\hline
\end{tabular}

Table 3. Mean DMFT among the Three Age Groups

\begin{tabular}{|c|c|}
\hline Independent variables & DMFT parameter estimate (SE) \\
\hline $\begin{array}{c}\text { Smoking } \\
\text { Smokers(p) }\end{array}$ & $\begin{array}{c}0.3(0.05) \\
0.01\end{array}$ \\
\hline $\begin{array}{l}\text { Age } \\
\text { p }\end{array}$ & $\begin{array}{c}1.3(0.6) \\
.02\end{array}$ \\
\hline
\end{tabular}

Table 4. Multiple Regression Analysis Linking DMFT with Other Parameters (Non-significant values have been omitted) 